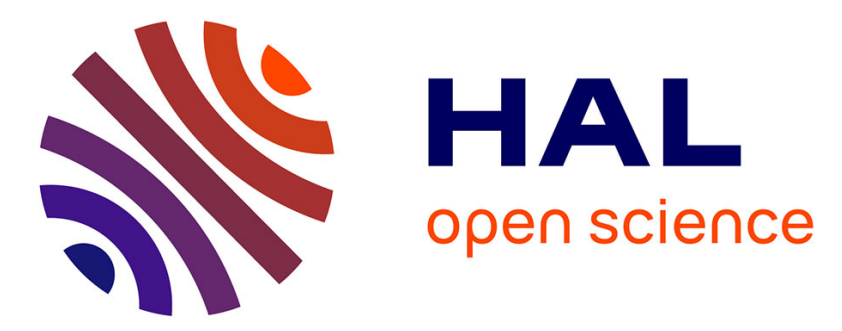

\title{
The Economic Value of an Emergency Call System
}

Tomas Lego, Andreas Mladenow, Niina Maarit Novak, Christine Strauss

\section{To cite this version:}

Tomas Lego, Andreas Mladenow, Niina Maarit Novak, Christine Strauss. The Economic Value of an Emergency Call System. 11th International Conference on Research and Practical Issues of Enterprise Information Systems (CONFENIS), Oct 2017, Shanghai, China. pp.56-66, 10.1007/978-3-319-948454_6. hal-01888633

\section{HAL Id: hal-01888633 \\ https://hal.inria.fr/hal-01888633}

Submitted on 5 Oct 2018

HAL is a multi-disciplinary open access archive for the deposit and dissemination of scientific research documents, whether they are published or not. The documents may come from teaching and research institutions in France or abroad, or from public or private research centers.
L'archive ouverte pluridisciplinaire HAL, est destinée au dépôt et à la diffusion de documents scientifiques de niveau recherche, publiés ou non, émanant des établissements d'enseignement et de recherche français ou étrangers, des laboratoires publics ou privés. 


\title{
The Economic Value of an Emergency Call System
}

\author{
Tomas Lego ${ }^{1}$, Andreas Mladenow ${ }^{1, *}$, Niina Maarit Novak $^{2}$, Christine Strauss $^{1}$ \\ ${ }^{1}$ University of Vienna, Department of e-Business, Faculty of Business, Economics \\ and Statistics, Oskar-Morgenstern-Platz 1 A-1090 Vienna, Austria, \\ \{tomas.lego, andreas.mladenow, christine.strauss\}@univie.ac.at \\ ${ }^{2}$ Vienna University of Technology, Institute of Information Systems Engineering, \\ Favoritenstr. 9-11, A-1040 Vienna, Austria \\ niina.novak@tuwien.ac.at
}

\begin{abstract}
Call is a complex solution, aimed at supporting drivers and car passengers in the event of an accident in Europe. This automatic emergency call system for motor vehicles, planned by the European Union, is installed in all new models of passenger cars and light commercial vehicles. In this context, the contribution analyses the monetary value of the eCall system implementation.
\end{abstract}

Keywords: eCall, Emergency Call, eCall Implementation, Monetary Value, Business Value, Value Creation, Economic Value.

\section{Introduction}

Information technologies (IT) and innovative solutions influence humanity both positively and negatively $[1 \div 6]$. In this context, modern technologies offer new solutions to well-established problems, e.g. automobile accidents. A good example of such an innovative solution is the automatic emergency call system (eCall) which will be implemented in the European Union beginning in March 2018 [7].

This IT solution is also important from the psychological point of view, since the need for safety is one of the basic needs of Maslow's well-known hierarchy of needs [8]. The development and search for an EU-wide implementation of the eCall system is only one evidence that this statement is still valid.

Still, such a system brings more than one solution to a specific problem and encompasses numerous aspects when considered thoroughly. Some of the effects of this safety system can be expressed in monetary values that will be analysed in this paper, which is structured as follows. Section 2 provides a brief overview of the development, the functions, and the necessary infrastructure of the technology. Section 3 focuses on positive and negative monetary and non-monetary aspects of the economic impacts of its implementation, which are further analysed from two different perspectives. Finally, Section 4 of the paper summarizes the initial findings and presents possible future developments for eCall. 


\section{Emergency Call System - functions and infrastructure}

The eCall system is part of the "Road Safety Strategy" which was launched by the European Union in 2010. The system is meant to work throughout the entire European Union based on the existing platform of a uniform emergency call number 112 [9], with the main goal to manage emergency calls. The general aim of the system's implementation can be summarized as "automating the notifications of traffic accidents from anywhere in the European Union and associated countries" [9].

In the event of an emergency, most likely a car accident, the system is either automatically or manually triggered and an emergency call is established [10]. The purpose of such a system is to facilitate the making of the call. It is especially helpful in situations when the passengers of the vehicle are not able to make the call themselves [11], e.g. in situations when an individual does not have a mobile phone to use for an emergency call. Furthermore, it provides an additional advantage as the system is not only meant to establish a voice connection, but also establishes data transfer. To ensure the operability of the system, the Public Safety Answering Points (PSAP), serving as callcentres receiving the emergency calls, must be upgraded and vehicles have to be equipped with in-vehicle devices, which will act as triggering mechanisms [10].

The implementation of an automatic notification system for emergency situations on roads has several goals. One of the main goals among these is to cut the number of road casualties in half by the year 2020. This is a significant challenge given that alone in the year 2014, there have been approximately 26,000 people who died as a consequence of a car accident in the European Union. Yet, the system does not only aim at lowering the number of human casualties on roads; but it aims as well at reducing the number and the severity of injuries in general [9]. Moreover, the introduction of the eCall system is also an attempt to unify the in-vehicle emergency systems within the European Union. As a matter of fact, many similar systems such as the "Volvo On Call" are operational throughout Europe [9]. However, these systems are voluntarily purchased by car-owners as optional add-on service and are not standard. Considering their benefits, this should change with the implementation of the eCall system.

eCall was introduced by the European Union in 2001 and was originally meant to be fully operational by 2009 [12]. However, in 2006 the European Commission postponed the desired year of implementation to 2010 [13], and again to October 2015 [14]. As of today, the system is to be launched in all EU-member states by 31 March 2018, making it mandatory that all new types of vehicles introduced after this date will have to be equipped with eCall technologies [15].

To ensure operability of the system, each EU-member country must equip and ensure that the infrastructure of all national Public Safety Answering Points (PSAP) is capable of receiving eCalls by 1 October 2017 at the latest. It must be guaranteed that all PSAPs work on the basis of the 112-emergency number [7], which was launched in 1991 [10] and is still active as a pan-European emergency call number. It should be highlighted that the eCall system is not meant to substitute this number, but is rather based on this well-established emergency call platform and should enable the triggering of an automatic emergency call from the inside of a vehicle. 
As indicated, the road towards an EU-wide implementation of the system was interrupted or postponed several times. However, the introduction of the EU "Road Safety Strategy" in 2010 marked the beginning of a more dynamic development [9]. One of the largest steps in ensuring a required level of preparedness of the European market was taken in 2011 when a pilot project co-founded by the European Union, referred to as the Harmonised eCall European Pilot (HeERO), was launched. For three years, the eCall system was tested in nine European countries. The number of these testing countries was increased with an additional six countries in January 2013, and the second stage of testing began. Furthermore, several other countries desired to join this pilot project, but their request was not successful. The goals which were followed by HeERO included: expressing a necessity of upgrading infrastructures to support the uniform eCall system, boosting investments into these, and generally preparing the entire area for the compulsory introduction of the system [9] by October 2017 [7].

To ensure full functional capacity of the eCall system, both vehicles and the infrastructure must be prepared accordingly. Vehicles have to be equipped with eCall technology consisting of an In-Vehicle System (IVS) that is capable of establishing an emergency call using a mobile network [16]. Further, this IVS is attached to collision detection sensors such as airbags or any other triggering sensors [17] that are integrated in the vehicle and is also connected to the audio-communication mechanisms of the car [9].

Once these devices are installed and operational within the vehicle, the system is able to work and can be activated in two ways. It can be triggered either automatically or manually. The automatic triggering is meant for serious accidents when the in-built sensors mentioned above detect an impact and independently initiate an emergency call [9]. The second method for activating the system is meant for cases when an individual witnesses another accident, when the car crash has not been so impactful that the system would have been triggered automatically [18], or for any other emergency case which has not evoked an automatic response by the vehicle.

The PSAP have to be prepared for handling eCalls to ensure a state of readiness within the infrastructure. This is a crucial premise since the PSAP do not only have to be able to establish a voice connection with the vehicle but are also required to be capable of decoding a bundle of digital information that is sent to them by the IVS. This information is often referred to as the minimum set of incident data (MSD) [10]. One of the main pieces of data which is transferred from the crashed car to the PSAP is a so called eCall Flag - a piece of information that is decodable by the answering points which clearly states that the incoming emergency call is an eCall [9]. The eCall Flag is crucial and especially valuable in situations when the passengers of the vehicle are not able to speak. If such a call would be not routed to an eCall-supported PSAP, the emergency call [19] would be defined as a silent call and would thus most probably be terminated by the operator.

However, knowing that it is not a silent call and given the MSD, the emergency call operator still has information to work with. Based on this, the operator is facilitated in making better, well-informed decisions and can arrange for the needed rescue services. In this regard, the MSD contains information such as the car's location, the direction in 
which it had been moving, the vehicle's description, the time [9], and whether the system was triggered automatically or manually [17]. Depending on whether the used PSAP is privately or publicly owned, additional information can be shared useful for road assistance or the Global Positioning System (GPS navigation) [9].

Once a call is triggered and the MSD is transferred, the system works in such a way that all installed microphones and loudspeakers in the vehicle are solely dedicated to the system and used as means of communication with the mobile operator. Interestingly enough, this connection can only be terminated by the PSAP and cannot be discontinued from inside the vehicle. Still, the audio systems within the car remain designated to the system in the event of a call back [9]. Generally, the establishment of a voice connection is primarily meant to be a source of additional information for the operator of the emergency call line [17]. The determination of the exact location of the car is complemented with the international GPS location [20]. Notably, these positioning services can also be provided by the European Galileo system [16].

\section{Analysis of non-monetary and monetary value}

\subsection{Non-monetary value}

More than two thirds of car accident-related emergency calls are not made by the people directly involved in the accidents [21] but are made by witnesses. This could be due to the fact that the victims of an accident are incapable of making these calls because of their injuries, but it can also be that those involved do not even realize the severity of the situation. This is often the case when occupants of a vehicle are intoxicated, under the influence of other addictive substances, or have suffered a severe shock or trauma during the crash itself. Thus, a system, which is able to make such a call automatically, would be of major importance. It is expected to reduce the notification delay in approximately one third of the cases. This equals an estimated net gain of ten minutes. Half of the fatalities occur exactly within these first minutes after an accident and only about a third of them occur in the hours following the crash [21]. Transforming this value into the number of saved lives, it may be expected, that up to 2,500 lives could be saved every year with the eCall technology [20]. Knowing that there have been 26,100 road fatalities solely in the year 2015 in the entire European Union [22], eCall technology could lead to a significant reduction in this number. If focusing only on Austria, the number of road casualties in 2015 was 479 . Considering it is $1.84 \%$ share of the number of fatalities in the entire EU, depending on the actual number approximately 46 people could be saved each year just in Austria [22].

The eCall system positively contributes in terms of saving lives by sharing the vehicle's location with the PSAP. However, even without the use of eCall, the legislation of the European Union anticipates such situations and obligates mobile network operators to provide the location of all 112-callers if asked by the PSAP [16]. Thus one could claim that the eCall system is redundant as this piece of information could be retrieved as well differently. When considering the system more thoroughly it becomes 
obvious that the IVS supply not only location data but a whole bundle of highly important information (see section 2).

One of the biggest reservations in connection to the implementation of a technology such as eCall is the concern for an individual's privacy. Thus it must be ensured that personal data cannot leak and that the system only communicates with a PSAP when triggered [9]. In addition, any continuous tracking achieved through the IVS should be impossible [11] and, even if it is transmitted to the responsible PSAP, the MSD should be handled according to the data protection rules that are valid within the European Union. However, despite these reassurances, official EU documents indicate that the information gained from IVS could be used for further developments in numerous areas. Besides other things, it could be of use to telecommunication-system providers and the car-industry to develop and propose new services and products [23].

Still, the extent of both positive and negative effects will greatly depend on the system's penetration rate [21]. In the year 2013, the European Union expected the penetration rate to reach $100 \%$ by the year 2033 [14]. Given the delayed starting date of implementation however, the maximum penetration rate will be reached only by 2035 , at the earliest [15].

\subsection{Monetary value}

Apart from the non-monetary value of eCall, the system also brings a lot of aspects that can be expressed in monetary values. These are factors which might not be obvious at first sight but are of great importance. Talking about monetary consequences associated with eCall not only involves the costs of installing eCall devices into vehicles but also the effects of reducing congestion, saving people's lives, and even using the data the system provides. In the following, this subsection will attempt to shed light on the less defined economic consequences of eCall. It will do so from two perspectives. First, there are areas within the private sector which are likely to be influenced through the introduction of the eCall system. Secondly, there is an even greater sphere of the economic background of automated emergency call systems in vehicles within the public sector. Thus, eCall does not only affect individuals but is important for society as a whole. Moreover, these monetary values are foreseen by the European Union itself [7] and are included in the "decision [...] of the European Parliament and of the council [...] on the deployment of the [...] EU-wide eCall service" [7] from the year 2014, stating that the service is also expected to provide monetary benefits to society by reducing congestion and secondary accidents as well as improving incident management [7].

The extent of the monetary values also greatly depend on the penetration rate of the system [21]. Once the desired $100 \%$ penetration rate is achieved and given the mandatory regulatory measures of eCall, the benefit-cost ratio is expected to reach 1.74 [14].

\subsubsection{Public Sector}

It is estimated that the public incurs costs of more than $€ 160$ billion per year due to vehicle accidents [16]. Through the introduction of eCall, the EU expects not only a 
reduction in the number of casualties, as outlined in the previous section, but also a significant reduction of these costs [20]. The cost reduction is estimated to reach up to $€ 20$ billion per year [10] and can be explained by a series of individual factors. The most prominent factors, frequently discussed in related literature include: the reduction of congestion, enhancing traffic services, improving accident management and saving human lives. Each of these factors can be measured in monetary values and will be further discussed in the following.

Traffic congestion is a very cost-intensive factor with regards to this evaluation. Disregarding the European Union, yearly costs of traffic congestion can amount to up to US\$23 billion for a single city. The city of Los Angeles for instance has to face this amount of costs on a yearly basis [24]. With regards to the EU, the costs of traffic congestion per city are not as staggering, however when investigating traffic congestion costs on a national level they can even surpass the frontier set by Los Angeles e.g. the United Kingdom estimated its costs caused by traffic congestion in the year 2003 to have reached up to US\$23.7 billion [25]. As it is hoped that eCall is to be used as a source of information for traffic management hubs, the number of secondary accidents could be lowered, and other drivers could be informed well in advance. Thus, eCall is also expected to help to reduce traffic jams by redirecting traffic to roads that are less congested [9]. Given these outlined scenarios, the portion of public costs due to traffic problems caused by congestion is expected to decrease.

Another aspect that can be expressed as monetary value is the price of a human life itself. Through the goal of reducing the number of fatalities and the severity of injuries [9], further savings could be achieved. Calculating the value of a human life however is a rather complex task. Even though it is a topic that has been targeted by scientists for more than several decades, a generally accepted equation for expressing this value does not exist. However, existing studies agree that the value of a human life depends on the contribution to society that would have been achieved by that individual [26]. Some of the determining values are age, gender, and the length and quality of education obtained by the potential victim [27]. Based on these values, it is possible to ascertain a monetary value expressing the loss to society caused by losing a human life, measured over the achievable lifetime earnings of the victim. Exact numbers will not be calculated at this point and the claim rather serves the goal of expressing the fact, that even the loss of a human life can be expressed as monetary value.

The total amount of costs to society caused by traffic accidents can be expressed as GDP-shares and amounted to 3.3\% of the Austrian GDP in the year 2012 [28]. This implies that without any costs related to traffic issues, the GDP of Austria would have not amounted to US $\$ 407.45$ billion [29] in 2012 but would have amounted to US\$421.3547 billion. Without doubt, a comparable improvement of Austria's GDP through the introduction of the eCall system, is not realistic. However, considering the forecasted savings' cap of $€ 20$ billion on the total costs of $€ 160$ billion per year, it could be expected that a similar positive change could have been witnessed in Austria as well. The positive change in the Austrian GDP would have accounted for up to $12.5 \%$ and could have led to a net gain of US\$1.74 billion on the GDP back in 2012. Since these amounts depend on the GDP value and the assumption that the $12.5 \%$ savings target is equal throughout all EU countries, the sums presented in this paragraph are only an 
approximation of the possible net-gains achievable through eCall. The exact equations are presented in Appendix.

Still, an introduction of eCall would not only be limited to savings, but would also offer countries new opportunities in terms of collecting revenues, e.g. collecting road charges, which is potentially accomplishable through the IVS [23].

\subsubsection{Private Sector}

The introduction of eCall presents as well opportunities for changes within the private sector. Some of these are also foreseen by the European Union itself [11].

PSAP can be either publicly or privately owned [21]. With private investors, the costs of updating these answering points would be relocated away from the state budget. Even though the costs of establishing and maintaining such a PSAP are not exactly defined, they are assumed to be substantial, given the fact that alone the needed servers are priced up to $€ 20,000$. Further costs include, among others, the expenses for the MSD-decoding software and training costs [14]. Regardless, the decision of letting private organizations take over the role of otherwise public sector-provided services must be taken well in advance and is both a money and time consuming matter, keeping in mind that these eCall-ready PSAP had to be fully operational by 1 October 2017 [7].

Despite the fact that emergency calls, even if made by eCall systems, are free of charge [7], the technology is of interest for various market players. Not only the automotive industry itself, but also telecommunication providers and many more could enhance their business models based on the mandatory introduction of this system [16]. Furthermore, eCall offers an opportunity for Third Party Services (TPS) which are also foreseen by the EU and are expected to work side-by-side with the PSAP [11].

Considering automated manufacturing processes and the desired degree of implementation, the costs for installing one fully operational eCall system into a vehicle will not exceed $€ 100$ [23]. Still, manufacturing the software and the hardware could be an interesting business opportunity and is already followed by some well-known companies, e.g. Bosch [30].

Yet, it is an interesting fact that there are no exact conditions under which the system has to be triggered automatically. The sensors have specified limits between which the system surely needs to be activated and when it cannot be activated. These frontiers are defined through UN regulations, but the exact amount of triggering-force expressed in any quantity is not exactly defined. Thus, there remains a small area between the two extreme points and it is the role of the producers of these systems to fine-tune the systems $[17,31]$. Based on this, a wide range of differently sensitive products can be expected whereby some might be automatically triggered after a small bump and other models which will not act in the same way. Therefore, it is likely that different segments within the market for eCall IVS will come into existence, influencing the revenues of automobile manufacturers.

An example of this influence could occur if it would become publicly known that the eCall systems of a certain car manufacturer are more likely to be triggered whereas those of another manufacturer might require greater forces to be activated. Considering two cars, each with a different eCall system, it is to be assumed that the mark and thus the type of the IVS installed might be of importance for people when deciding between 
the two vehicles. These can be substituted by the IVS and thus a decision between these two cars might be based on the preferences of a driver to own a car which either can be seen as safer since the triggering force set in the IVS is lower or one which has a less sensitive system and thus does not report a little bump when parking the car. Even though this example might be exaggerated and these diverse preferences surely go hand in hand with the different types of drivers, even this could influence customers' choices when purchasing a vehicle. Consequently, car manufacturers could be affected as well through the choice of which IVS they use. Such a connection seems more than plausible. However, the relevance of it would have to be further examined.

Another sector, which could be heavily influenced through the introduction of eCall is the insurance market. Retrieved data from IVS could be used for determining accident causes, it could speed up the process of handling individual cases and it could even be used for revealing insurance scams. Further, it could be used for the automatic processing of administrative procedures and could even help to fight car-theft related crimes [32]. It is a fact that such improvements would influence thousands of people but, since insurance companies are profit-oriented and, not state owned organizations, even this effect is to be classified as influencing the private sector above all.

\section{Conclusion and Outlook}

The eCall system is a complex solution that provides matters of assisting to make an emergency call in the case of an accident in Europe. Not only does it show its potential in terms of saving lives and reducing the consequences of car accidents in general, it can be further seen in a different light if looked at by an economist. There are many areas of the private sector influenced by this system, and there are also numerous areas within the public sector that are not independent of the eCall system. Furthermore, these influences can be categorized, subject to the sector they affect. Thus, we can diversify between private and public sector related consequences of the mandatory introduction of eCall.

Future developments promise further improvements and enhanced features. This very fact also applies to eCall, which is expected to provide even a two-way data transfer in the future. Not only will the PSAP be able to receive data from vehicles, it will also have the option of sending instructions to the car itself. This means that the PSAP will be given the option of remotely sounding the horn of the crashed vehicle, unlocking its doors, switching its lights on and off, or letting them flash [9]. The two-way data transfer could also be used for establishing a video transfer between the vehicle and the corresponding PSAP [33].

The development and procuring of its operability were not uncomplicated and have been going on for more than a decade now. Nevertheless, as well the eCall technology is expected to further develop and offer more features in the future. 


\section{References}

1. Brasseur, T.M., Mladenow, A., Strauss, C.: "Business Model Innovation to Support Smart Manufacturing" (2017). American Conference on Information Systems 2017 Workshop on Smart Manufacturing (AMCIS). Proceedings. 9. URL: http://aisel.aisnet.org/sigbd2017/9

2. Bauer, C., Mladenow, A., Strauss, C.: "Fostering collaboration by location-based crowdsourcing". In International Conference on Cooperative Design, Visualization and Engineering, CDVE, 88-95 (2014).

3. Mladenow, A., Novak, N. M., Strauss, C.: "Internet of things integration in supply chainsan Austrian business case of a collaborative closed-loop implementation". In Research and Practical Issues of Enterprise Information Systems: 10th IFIP WG 8.9 Working Conference, CONFENIS 2016, Vienna, Austria, December 13-14, 2016, Proceedings 10, 166176 (2016).

4. Mladenow, A., Novak, N. M., Strauss, C.: "Online ad-fraud in search engine advertising campaigns". In Information and Communication Technology, 109-118. Springer, Cham. LNCS 9357 (2015).

5. Ernst, C., Mladenow, A., Strauss, C.: "Collaboration and crowdsourcing in emergency management". International Journal of Pervasive Computing and Communications, 13(2), 176-193 (2017).

6. Mladenow, A., Bauer, C., Strauss, C. "Crowd logistics": the contribution of social crowds in logistics activities. International Journal of Web Information Systems, 12(3), 379-396 (2016).

7. EU Decision No. 585/2014/EU: "Decision No 585/2014/EU of the European parliament and of the council of 15 May 2014 on the deployment of the interoperable EU-wide eCall service"; URL: http://eur-lex.europa.eu/legal-content/EN/TXT/?uri=celex:32014D0585 ; last accessed 2017/08/30

8. Maslow, A.H.: "A theory of human motivation". Psychological review, 50(4), 370-396 (1943).

9. Iparraguirre, O., Brazalez, A.: "Communication Technologies for Vehicles: eCall", in: Proceedings of the 10th International workshop on Communication Technologies for Vehicles, 103-110 (2016).

10. Cabo, M., Fernandes, F., Pereira, T., Fonseca, B., Paredes, H.: "Universal access to eCall system”, in: Procedia Computer Science (27), 104-112 (2014).

11. EC: Commission Delegated Regulation: "European Commission Delegated Regulation (EU) of 12.9.2016"; URL: http://ec.europa.eu/transparency/regdoc/rep/3/2016/EN/C2016-5709-F1-EN-MAIN-PART-1.PDF ; last accessed 2017/08/30

12. CotEC: "Commission of the European communities: The 2nd eSafety Communication, Bringing eCall to citizens" / "Druhé sdělení o e-bezpečnosti, Zpř́istupnění systému eCall Občanům"; URL: http://eur-lex.europa.eu/legal-content/EN/ALL/?uri=CELEX:52005DC0431; last accessed 2017/08/30

13. CotEC: "Commission of the European communities: Bringing eCall back on track - Action Plan (3rd eSafety Communication)"; URL: http://eur-lex.europa.eu/legal-content/EN/ALL/?uri=CELEX\%3A52006DC0723 ; last accessed 2017/08/30

14. EC: eCall Deployment proposal: "Proposal for a decision of the European parliament and of the council on the deployment of the interoperable EU-wide eCall"; URL: http://eurlex.europa.eu/legal-content/EN/TXT/PDF/?uri=CELEX:52013PC0315\&from=EN ; last accessed 2017/08/30 
15. EENA: "eCall, Everything you wanted to ask, but did not know how..."; URL: http://www.eena.org/download.asp?item_id=111; last accessed 2017/08/30

16. Chochliouros, I.P., Spiliopoulou-Chochliourou, A.S., Lalopoulos, G.K.: "Emergency call (eCall) Services based on approved E-112 regulations and infrastructures: a solution to improve security and release of road help", in: FITCE Congress, 76-84 (2005).

17. Harnischmacher, F, Cosyns, C., Grugl, K., Moerbe, M., Portouli, E., Savaresi, S.M.: "State of the art assessment Powered Two-Wheeler (P2W) eCall"; in: 11th ITS European Congress ; URL: https://dl.dropboxusercontent.com/content_link/Nv6xtkIjnWqeZ5dyZdKS7EiY2RTK6AfnHkAHkOI4hGE1BCqkB4FyRtxk0gB CYROz/file ; last accessed 2017/08/30

18. HeERO: "About eCall, eCall: eCall - saving lives through in-vehicle communication technology“; URL: http://www.heero-pilot.eu/view/en/ecall.html ; last accessed 2017/08/30

19. Carutasu, G.: "Further challenges of eCall service and infrastructure", in: MIT 2016 Conference proceedings, 68-72 (2016).

20. Chariete, A., Bakhouya, M., Nait-Sidi-Moh, A., Ait-Cheik-Bihi, W., Gaber, J, Kouta, R., Wack, M, Lorenz, P.: "A study of users' acceptance and satisfaction of emergency call service”, in: International Journal of Communication Systems, 2279-2291 (2016).

21. Sihvola, N., Luoma, J., Schirkoff, A., Salo, J., Karkola, K.: "In-depth evaluation of the effects of an automatic emergency call system on road fatalities", in: European Transport Research Review 1 (3), 99-105 (2009).

22. EC Road Fatalities: "EU road fatalities" ; URL: http://ec.europa.eu/transport/road_safety/sites/roadsafety/files/pdf/observatory/trends_figures.pdf ; last accessed 2017/08/30

23. EU: Summary for citizens: "Shrnutí určené občanům: Návrh EU zavést systém palubního tísňového volání eCall pro oznamování dopravních nehod“; URL: http://ec.europa.eu/information_society/activities/esafety/doc/comm_20090821/citizens_sum_cs.pdf, last accessed 2017/08/30

24. McKinsey\&Co: "An integrated perspective on the future of mobility"; URL: http://www.mckinsey.com/business-functions/sustainability-and-resource-productivity/our-insights/an-integrated-perspective-on-the-future-of-mobility ; last accessed 2017/08/30

25. Lindsey, R., De Palma, A.: "Traffic congestion pricing methodologies and technologies"; in: Transportation Research Part C: Emerging Technologies 19 (6), 945-1400 (2011).

26. Card, W.I., Mooney, G.H.: "What is the monetary value of human life?"; in: British Medical Journal, 1977 (2), 1627-1629 (1977).

27. Rice, D.P., Cooper, B.S. (1967): “The economic value of human life"; in: American Journal of Public Health Nations Health Vol. 57, Iss. 11, pp. 1954-1966

28. WHO: "Country profiles"; in: Global status report on road safety 2015 World Health Organization; pp. 76-256 ; URL: http://www.who.int/violence_injury_prevention/road_safety_status/2015/en/ ; last accessed 2017/08/30

29. Worldbank: "GDP (current US\$)"; URL: http://data.worldbank.org/indicator/NY.GDP.MKTP.CD?end=2012\&start=1960 ; last accessed 2017/08/30

30. Bosch: "Das Automatische Bosch Notrufsystem eCall für Automobile"; URL: http://www.bosch-presse.de/pressportal/de/de/das-automatische-bosch-notrufsystem-ecallfuer-automobile-42801.html ; last accessed 2017/08/30 
31. Spreitzer, S., Mladenow, A., Wagner, G.: "IT-getriebenes Instandhaltungsmanagement im After Sales Bereich”. HMD Praxis der Wirtschaftsinformatik 54 (3), 437-451 (2017).

32. Hornung, G.: "Verfügungsrechte an fahrzeugbezogenen Daten", in: Datenschutz und Datensicherheit, 359-366 (2015)

33. los Santos Aransay, A., Reina Nieves, A, Rueda Morales, C., Ares, F., Saez Gomez, J., Martinez Madrid, N., Sanz Velasco, P., Seepold, R.: "Integration of an advanced emergency call subsystem into a car-gateway platform“, in: Design, Automation \& Test in Europe Conference \& Exhibition, 1100-1105 (2009).

\section{Appendix}

For Austria:

US $\$ 407.45$ billion GDP in the year 2012 [25]

$3.3 \%$ GDP loss due to traffic accidents [24]

US $\$ 421.3547$ billion $=$ potential GDP without these accidents

$$
x=\frac{407.45}{1-0.033}=421.3547
$$

$€ 20$ billion possible savings [6] on the $€ 160$ billion costs throughout the entire EU [12]

$12.5 \%=$ expected upper bound on the cost savings

$$
x=\frac{20}{160}=0.125=12.5 \%
$$

US $\$ 13.9047$ billion $=$ the potential net gain by $100 \%$ reduction in the costs of traffic accidents

$$
x=421.3547-407.45=13.9047
$$

US $\$ 1.7380875$ billion $=$ the expected upper bound for the net gain in GDP

$$
x=13.9047 * 0.125=1.7380875
$$

